Tropical Journal of Pharmaceutical Research March 2021; 20 (3): 613-620

ISSN: $1596-5996$ (print); 1596-9827 (electronic)

(C) Pharmacotherapy Group, Faculty of Pharmacy, University of Benin, Benin City, 300001 Nigeria.

Available online at http://www.tjpr.org

Original Research Article

http://dx.doi.org/10.4314/tjpr.v20i3.25

\title{
In vitro antidiabetic, aphrodisiac and antimicrobial properties of para-propoxybenzoic acid isolated from Acacia auriculiformis A. Cunn Ex. Benth (Fabaceae) stem bark
}

\author{
Ekarika C Johnson ${ }^{1 *}$, Richard A Ukpe ${ }^{2}$, Emmanuel I Etim ${ }^{1}$, Uwemedimoh F \\ Umoh $^{3}$, Olorunfemi A Eseyin ${ }^{1}$, Anwanabasi E Udoh, Tina Mboho', Paschal C \\ Anthony ${ }^{1}$ \\ ${ }^{1}$ Department of Pharmaceutical and Medicinal Chemistry, ${ }^{2}$ Department of Chemistry, Federal University, Otuoke, Bayelsa \\ State, ${ }^{3}$ Department of Pharmacognosy and Natural Medicine, ${ }^{4}$ Department of Pharmacology and Toxicology, Faculty of \\ Pharmacy, University of Uyo, Uyo, Nigeria
}

*For correspondence: Email: rikaisable@gmail.com; Tel: +234-7037476173

Sent for review: 9 October 2020

Revised accepted: 18 February 2021

\begin{abstract}
Purpose: To investigate the in vitro antidiabetic, aphrodisiac and antimicrobial properties of parapropoxybenzoic acid isolated from Acacia auriculiformis stem bark.

Methods: Powdered dried stem bark of A. auriculiformis was extracted with $70 \%$ ethanol in water and the dried extract obtained was suspended in water and partitioned with ethyl acetate and $n$-butanol to give their respective soluble fractions. The ethyl acetate fraction being more active, in terms of in-vitro aphrodisiac, antidiabetic and antimicrobial properties, was subjected to chromatographic separation to obtain C1 identified as parapropoxybenzoic acid, which was also evaluated for in-vitro properties using standard procedures.

Results: 4-Propoxybenzoic acid showed a weak aphrodisiac property which was not significantly different $(p<0.05)$ from that of control (normal saline) for all the sexual parameters tested. The compound exhibited antidiabetic activity by dose-dependently inhibiting the actions of $\alpha$-amylase with half-maximal concentration (IC50) value of $50 \pm 0.45 \mu \mathrm{g} / \mathrm{mL}$. In this regard, it was comparable to that of the standard, acarbose $(30 \pm 0.18 \mu \mathrm{g} / \mathrm{mL})$. In the antimicrobial study, a concentration of $200 \mu \mathrm{g} / \mathrm{mL}$ of the compound gave the highest zone of inhibition of $18 \pm 0.23 \mathrm{~mm}$ against Vibo cholriae (NCTC 5438) Conclusion: The results indicate that the isolated compound, 4-propoxybenzoic, exhibits good antidiabetic and anti- microbial but weak aphrodisiac properties.
\end{abstract}

Keywords: Acacia auriculiformis, Aphrodisiac, Antidiabetic, Antimicrobial, Para-propoxybenzoic acid, Antidiabetic, Acarbose, Erythromycin, Fluconazole

This is an Open Access article that uses a fund-ing model which does not charge readers or their institutions for access and distributed under the terms of the Creative Commons Attribution License (http://creativecommons.org/licenses/by/4.0) and the Budapest Open Access Initiative (http://www.budapestopenaccessinitiative.org/read), which permit unrestricted use, distribution, and reproduction in any medium, provided the original work is properly credited.

Tropical Journal of Pharmaceutical Research is indexed by Science Citation Index (SciSearch), Scopus, International Pharmaceutical Abstract, Chemical Abstracts, Embase, Index Copernicus, EBSCO, African Index Medicus, JournalSeek, Journal Citation Reports/Science Edition, Directory of Open Access Journals (DOAJ), African Journal Online, Bioline International, Open-J-Gate and Pharmacy Abstracts

\section{INTRODUCTION}

Phytochemicals are natural chemical compounds produced by plants. They are non-nutritive but are needed by plants for purposes such as disease and pathogen defense and control [1]. Studies have shown that phytochemicals are essential in human health maintenance. This is 
because they display different good health promoting properties by acting as antioxidant, anti-inflammatory, anticancer antimicrobial agents, etc [2]. Plant-derived substances have recently become of great interest due to their broad applications [3]. Medicinal plants are the richest biosource of drugs in traditional systems of medicine, modern medicine, nutraceuticals, food supplements, folk medicines, pharmaceutical intermediates and chemical entities for synthetic drugs [4]. It has been estimated that $14-28 \%$ of higher plant species are used medicinally, and that $74 \%$ of pharmacologically-active plant-derived components were discovered after following up on ethnomedicinal uses of the plants [5].

A number of interesting outcomes have been found with the use of mixture of natural products to treat diseases; most notably are the synergistic effects and polypharmacological applications of plant extracts [6]. The production of pharmaceuticals starts with the identification of bio-active compounds, detailed biological assay and dosage formulations, followed by clinical studies to establish safety, efficacy and pharmacokinetic profile of the new drug [7]. This is also true for therapeutic agents from plants. Thorough biological evaluation of plant extracts is vital for ensuring their efficacy and safety. These factors i.e., efficacy and safety, are important to qualify the plant extracts as valid medicinal agents [8].

Natural products play an important role in the field of new drug research and development because of their low toxicity, ready availability and cost effectiveness [9]. A. auriculiformis is a medicinal plant known for several potent pharmacological activities including anthelmintic, antifilarial and microbicidal properties $[10,11]$.

An extract produced from the root of the plant is known to be useful in the treatment of sore eyes and various aches. The Aborigines of Australia are known to use the bark extracts of this plant to treat rheumatism [12]. Various extracts of this plant have demonstrated antioxidant benefit [13]. The seeds of this plant are reported to produce triterpenoid saponins namely: acaciaside A (AcA) and acaciaside B (Ac-B); and earlier investigations showed that $A c-B$ possessed spermicidal activity even at significantly low concentrations [14]. Experiments by Kabir et al [14] showed that such extract can also inhibit HIV transmission without any mutagenic effect.

A recent study has revealed that an ointment prepared from ethanol and aqueous extracts of stem bark of $A$. auriculiformis evaluated for wound healing property showed extensive healing activity by enhancing wound contraction, shortening epithelization period with increased tensile strength [15]. The pesticidal action of the stem bark extracts of the plant has also been reported [16]. Studies have shown that $A$. auriculiformis has many pharmacological properties but the information available on this plant indicates that attention is devoted to studying mostly the leaf and the seed parts. This research work was designed to investigate the pharmacological effect of the ethanol stem bark extract of $A$. auriculiformis with the aim of establishing the presence or lack of aphrodisiac, antidiabetic and antimicrobial potential as well as isolating and identifying the compounds responsible for the properties.

\section{EXPERIMENTAL}

\section{Equipment and reagents}

Gradient elution column chromatography was performed on Silica Gel G 60-120 mesh (Loba Chimie, India); analytical and preparative thin layer chromatography were performed on Precoated silica gel G TLC plates (aluminium backed, $0.2 \mathrm{~mm}$, and silica gel $\mathrm{G}$, glass backed, $0.5 \mathrm{~mm})$. The melting point of the isolated compound was determined using the Scientific Instruments (India). The Nuclear Magnetic Resonance (NMR) spectroscopic analysis was performed using Agilent NMR-vnmrs 400 (400 $\mathrm{MHz}$, USA) run on $\mathrm{CD}_{3} \mathrm{OD}$ at $31^{\circ} \mathrm{C}$ for ${ }^{1} \mathrm{H}$ and ${ }^{13} \mathrm{C}$ NMR using TMS as internal standard with drops of $\mathrm{CD}_{3} \mathrm{OD}$ previously added to dissolve the sample. The Fourier Transform Infra-Red (FTIR) spectroscopic analysis was done using transmittance method on Agilent FTIR (USA) on $\mathrm{KBr}$ disc and the signals measured in $\mathrm{cm}^{-1}$. All solvents, $17 \beta$-estradiol, progesterone, testosterone, sodium phosphate, enzyme, 3, 5dinitrosalicylic acid, acarbose, erythromycin, fluconazole and Streptomycin were obtained from Sigma-Aldrich chemicals, (USA) and S.D. Fine Chemicals Limited (India).

\section{Extraction and isolation of $\mathrm{Cl}$}

The fresh stem bark plant materials of Acacia auriculiformis were collected in the month of June 2019, authenticated by the herbarium at the Department of Pharmacognosy, Faculty of Pharmacy, University of Uyo, dried under shade for some weeks and pounded to powder using mortar and pestle. A herbarium specimen with voucher number UUPH 14d was prepared and deposited in the Herbarium. The dried powder of the plant material $(0.5 \mathrm{~kg})$ was exhaustively extracted using $70 \%$ ethanol $(3 \times 5 \mathrm{~L})$ at room 
temperature $\left(27 \pm 2{ }^{\circ} \mathrm{C}\right)$ for $72 \mathrm{~h}$. The resultant crude extract was filtered, concentrated in vacuo on a rotary evaporator (R-3, CH-9230, BuchiLab Switzerland), weighed and stored in a desiccator (Monsori, Scotland) prior to further use. The crude extract $(50.0 \mathrm{~g})$ was partitioned using ethyl acetate and butanol (4 x $500 \mathrm{~mL}$ each) to obtain ethyl acetate (EA) and n-butanol (BUOH) fractions, respectively. The EA fraction that had higher positive response to the pharmacological tests was subjected to chromatographic separation. Briefly, the EA fraction $(2.0 \mathrm{~g})$ was chromatographed on the silica gel in a column (3x50 cm, Pyrex, USA) and eluted with a gradient elution solvent system - chloroform: methanol in increasing polarity starting with the ratio 99:1. Eluates (5 mL each) were collected, monitored on silica TLC plates (Merck, Germany) in Acetone: toluene: Water (10:20:1) using 10\% sulphuric acid in methanol and vanillin-sulphuric acid as spray reagents.

Fractions with similar TLC characteristics $\left(R_{f}\right.$ values, colour reaction with spray reagents) were bulked to give three semi-pure residues coded T1 - T3. T1 and T3 were difficulty to purify further and were discarded. T2 was purified using preparative TLC; dried T2 $(0.15 \mathrm{~g})$ was carefully dissolved in methanol and applied across the coated silica gel plate $(20 \times 20 \mathrm{~cm}, 0.25 \mathrm{~mm})$ using a micro-Pasteur pipette (Simax, India) 1 $\mathrm{cm}$ above the bottom edge of the plate. The plates were developed using nhexane:dichloromethane:methanol (1:4:1) solvent system in a Chromatank (USA). The chromatogram obtained showed two distinctly resolved layers which were carefully scrapped, separated, filtered, recrystallized in methanol and concentrated in vacuo. Further TLC evaluations indicated a single spot in one of the layers. This was stripped of the solvent to give a light brown solid coded $\mathrm{C} 1$ with $\mathrm{R}_{\mathrm{f}}$ of 0.49 (Acetone: Toluene: Water (10:20:1). The chemical structure of $\mathrm{C} 1$ was elucidated using a combination of physical and spectroscopic analyses.

\section{Determination of aphrodisiac activity}

Twenty (20) sexually mature male Wistar albino rats weighing $150-250 \mathrm{~g}$ were randomly assigned into five groups of four animals each with a distinct identity. Groups 1-3 received $136.93 \mathrm{mg} / \mathrm{kg}, 273.86$ and $410.79 \mathrm{mg} / \mathrm{kg}$ of the extract (representing low dose (LD), middle dose (MD) and high dose (HD) respectively) and 50 $\mu \mathrm{g} / \mathrm{mL}$ of $\mathrm{C} 1$ interparietally (ip), while Group 4 received $10 \mathrm{ml} / \mathrm{kg}$ of normal saline as the negative control and group 5 received $1 \mathrm{mg} / \mathrm{kg}$ of testosterone, administered subcutaneously (sc) as the positive control. The duration of this experiment was seven days. The experimental protocol was approved by the Faculty of Pharmacy, University of Uyo Research Animal Ethics Committee (Ref No. UU/PHM/RAEC/VOL $1 / 106)$ and the study was carried out according to NIH Guidelines for Care and Use of Laboratory Animals [17].

\section{Assessment of sexual behaviour}

The females were brought to oestrous cycle by administering $1 \mathrm{mg} / \mathrm{kg} 17 \beta$-estradiol $48 \mathrm{~h}$ and 0.5 $\mathrm{mg} / \mathrm{kg}$ body weight of progesterone $4 \mathrm{~h}$ (sc) prior to the commencement of the experiment to make them receptive to the male rats. The mating behaviour studies were carried out in a separate room under red source of light between (the dark period of) 7 - $9 \mathrm{pm}$, with the females introduced to the male rats $30 \mathrm{~min}$ apart. Initially, the male rat was kept in a transparent plexiglass copulation cage $(46 \mathrm{~cm} \times 41 \mathrm{~cm} \times 41 \mathrm{~cm})$ for 10 min, followed by introduction of the female. The following mating behavioural parameters were observed and recorded: mount frequency (MF), intromission frequency (IF), mount latency (ML), intromission latency (IL), ejaculation latency (EL), post-ejaculatory interval (PEI), ejaculation frequency (EF) and penile erection (PE) [18]. The values of the observed parameters were compared with those of the control [19]. All the experiments were performed in triplicates.

\section{Determination of inhibitory activity of $\alpha$ - amylase}

This procedure was carried out as reported by Johnson et al [20]. The assay mixture comprising $200 \mu \mathrm{L}$ of $0.02 \mathrm{M}$ sodium phosphate buffer, 20 $\mu \mathrm{L}$ of enzyme and the crude ethanol extract, prepared in the concentrations of $20,40,60,80$ and $100 \mathrm{mg} / \mathrm{mL}$ was incubated for $10 \mathrm{~min}$ at room temperature, followed by addition of $200 \mu \mathrm{L}$ of $1 \%$ starch $(1.0 \mathrm{~g}$ of starch in $100 \mathrm{~mL}$ of $20 \mathrm{mM}$ sodium phosphate buffer at $\mathrm{pH}, 6.8$ ) to all the test tubes. The reaction was terminated by addition of $400 \mu \mathrm{L}$ of 3, 5-dinitrosalicylic acid, placed in boiling water for $5 \mathrm{~min}$, cooled and diluted with $15 \mathrm{~mL}$ of distilled water. The absorbance of the extract was measured at 540 $\mathrm{nm}$. This procedure was repeated for the EA fraction, the isolated compound, $\mathrm{C} 1$ and the reference drug. Inhibition $(\mathrm{H})$ was calculated as in Eq 1.

$H(\%)=\{(\mathrm{Ac}-\mathrm{Ae}) / \mathrm{Ac}\} 100 \ldots \ldots(1)$

where Ac and Ae are the absorbance of control and extract samples, respectively. 
The concentration of the test samples required to inhibit $50 \%$ of the enzymes' action was defined by the $\mathrm{IC}_{50}$ value determined from the plot of percentage inhibition against log of inhibitor concentration and was calculated by non-linear regression analysis from the mean of inhibitory values. Acarbose was used as the reference $\alpha$ amylase inhibitor. All the tests were performed in triplicates.

\section{Antimicrobial studies}

Antimicrobial studies on the ethanol stem bark extract, ethyl acetate fraction and butanol fraction of the extract of $A$. auriculiformis were carried out using agar-well diffusion method. The microorganisms, namely: Bacillus subtilis (NCTC 8853), Staphylococcus aureus (NCTC 6872), Escherichia coli (NCTC 10764), Vibrio choleriae (NCTC 5438) and Candida albicans (NCYC 4366) were clinical isolates from specimens of urine, abscesses, necrotizing fascitis, osteomyelitis, diarrheal stool, wounds and vaginal swabs collected from the Medical Laboratory, University of Uyo Health Centre. The clinical isolates were collected in sterile bottles, identified and classified by convectional biochemical tests $[21,22]$ and then refrigerated at $-5{ }^{\circ} \mathrm{C}$, prior to use. Standard procedure of the hole-in-plate agar diffusion method was strictly applied using nutrient agar for the bacteria and Sabouraud Dextrose Agar (Oxoid, England) for the fungus. Pre-labelled plates were seeded with test organisms (sub cultured overnight) and 20 $\mathrm{mL}$ of molten agar poured into the plates and swirled to mix. The agar was allowed to solidify. Using a $4 \mathrm{~mm}$ diameter cork borer, wells were bored on the agar plates in which $0.1 \mathrm{~mL}$ of the various extracts were placed after carrying out two-fold serial dilution to get the concentrations; $200,100,50$ and $25 \mathrm{mg} / \mathrm{mL}$. The standard antimicrobial agents (erythromycin, streptomycin and fluconazole, $10 \mu \mathrm{g} / \mathrm{mL}$ each) were introduced accordingly. The inoculated plates were allowed to stand for $30 \mathrm{~min}$ for proper diffusion, and then incubated at $37{ }^{\circ} \mathrm{C}$ for $24 \mathrm{~h}$ [23]. The isolated compound (C1) was also evaluated for antimicrobial activity applying the same procedures and conditions used for the extracts, at concentrations of 200, 100, 50, and $25 \mu \mathrm{g} / \mathrm{mL}$. Antimicrobial property was determined by measuring the diameter of zones of inhibition produced after incubation. Each test was performed in triplicate.

\section{Statistical analysis}

All tests were carried out in triplicates and values expressed as mean \pm SEM. The data obtained were subjected to one-way analysis of variance
(ANOVA) and significant difference was determined using Turkey's multiple comparison tests with the aid of GraphPad prism software, version 5.03, at $p<0.05$ confidence level.

\section{RESULTS}

\section{Spectral characteristics of $\mathbf{C} 1$}

C1 was obtained as light brown amorphous powder, $\mathrm{mp} 147{ }^{\circ} \mathrm{C}$. The molecular formula $\mathrm{C}_{10} \mathrm{H}_{12} \mathrm{O}_{3}$ was determined on the basis of El-MS. (calcd. 180.00 for $\mathrm{C}_{10} \mathrm{H}_{12} \mathrm{O}_{3}$ ). On the FTIR spectrum the following peaks were identified: 3295. (OH); 2922.2 (C-H); 1169.97 (C=O) 1606.0 (C=C stretch) 1196.5 (C-O) and 1110.7 (phenolic $\mathrm{C}-\mathrm{O})$, 838.7. For the proton NMR peaks were identified as follows: $\delta_{H} 7.049$ (aromatic), 6.806 (aromatic) $4.072\left(-\mathrm{OCH}_{2}-\right) ; 1.794\left(\mathrm{CH}_{2}\right) \quad 0.900$ $\left(\mathrm{CH}_{3}\right.$ ) (see Figure $1 \mathrm{a}$ ); For C-13 NMR spectrum the following diagnostic peaks were identified: $\delta_{c}$ 172.976 (-COOH), 162.765(Ar - C-O-), 134.224(Ar=CH), $129.033 \quad(\mathrm{Ar}=\mathrm{CH}), \quad 115.648$ $(\mathrm{Ar}=\mathrm{CH}), 62.936\left(\mathrm{CH}_{2}\right), 26.000\left(\mathrm{CH}_{2}\right) ; 16.036$ $\left(\mathrm{CH}_{3}\right)$ (see Figure $1 \mathrm{~b}$ ).<smiles>[Y6]c1c([18OH])c(OCCCC)c([18OH])c([14CH2])c1C(=O)O</smiles><smiles>CCC(C)COc1cccc(C=O)c1</smiles>

Figure 1: (a) Structure of $\mathrm{C} 1$ showing proton NMR peaks; (b) structure of $\mathrm{C} 1$ showing $\mathrm{C}-13$ NMR peaks

Table 1 shows the results of the effect of test samples, the isolated compound $\mathrm{C} 1$ and the control drugs on sexual behaviour of the male rats

\section{Antidiabetic properties of the plant samples}

Table 2 shows the result of inhibitory actions of the extract, fractions, the isolated compound $\mathrm{C} 1$ and the standard drug (acarbose) on a-Amylase inhibitory activity of $A$. auriculiformis. 
Table 1: Summary of effect of test samples on sexual behaviour in male rats

\begin{tabular}{|c|c|c|c|c|c|c|c|c|}
\hline Dose (mg/kg) & ML & MF & IL & IF & EL & PEI & EF & PE \\
\hline Normal Saline $(10 \mathrm{ml} / \mathrm{kg})$ & $0.64 \pm 0.28^{a}$ & $6.50 \pm 1.28^{b}$ & $1.17 \pm 0.17^{\mathrm{c}}$ & $5.00 \pm 0.82^{d}$ & $4.73 \pm 0.41^{e}$ & $7.81 \pm 1.27^{f}$ & $3.50 \pm 1.29^{h}$ & $6.73 \pm 1.26^{i}$ \\
\hline Testo $(1 \mathrm{mg} / \mathrm{kg})$ & $0.22 \pm 0.09^{j}$ & $7.50 \pm 2.65^{k}$ & $0.46 \pm 0.06^{1}$ & $6.85 \pm 2.22^{m}$ & $1.64 \pm 0.46^{n}$ & $2.77 \pm 0.61^{\prime}$ & $6.25 \pm 2.63^{\circ}$ & $2.21 \pm 0.46^{p}$ \\
\hline C1 $(50 \mu \mathrm{g} / \mathrm{mL})$ & $0.61 \pm 0.003^{a}$ & $0.65 \pm 0.002^{b}$ & $\underset{c}{1.11 \pm 0.005}$ & $5.01 \pm 0.005^{d}$ & $4.61 \pm 0.002^{e}$ & $7.68 \pm 0.004^{f}$ & $3.60 \pm 0.001^{\mathrm{h}}$ & $6.40 \pm 0.005^{i}$ \\
\hline EA. (LD; $136.90 \mathrm{mg} / \mathrm{kg})$ & $0.64 \pm 0.28^{a}$ & $6.50 \pm 1.29^{b}$ & $1.17 \pm \underset{c}{ \pm} 0.17$ & $5.00 \pm 0.82^{d}$ & $4.73 \pm 0.41^{\mathrm{e}}$ & $7.81 \pm 1.27^{f}$ & $3.50 \pm 1.29^{h}$ & $6.73 \pm 1.26$ \\
\hline EA (MD; $273.86 \mathrm{~m}$ & $0.69 \pm 0.29^{a}$ & $6.50 \pm 1.29^{b}$ & $1.98 \pm \underset{c}{0} 0.30$ & $5.50 \pm 1.73^{d}$ & $4.58 \pm 0.60^{e}$ & $7.67 \pm 1.17^{f}$ & $3.50 \pm 1.00^{h}$ & $6.48 \pm 0.96^{i}$ \\
\hline EA. (HD;410.79 mg/kg) & $0.64 \pm 0.39^{a}$ & $6.75 \pm 1.71^{b}$ & $1.15 \pm 0.14$ & $5.05 \pm 2.22^{d}$ & $4.60 \pm 0.89^{e}$ & $7.80 \pm 0.97^{f}$ & $3.25 \pm 2.22^{h}$ & $6.71 \pm 0.92^{i}$ \\
\hline
\end{tabular}

Values are expressed as mean \pm SEM( $n=3)$; data with different letters are significantly different at ${ }^{*} p<0.05$. Key: Testo $=$ Testosterone; EA. $=$ Ethyl acetate fraction; LD = low dose; $\mathrm{MD}=$ middle dose; $\mathrm{HD}=$ high dose; $\mathrm{MF}=$ mount frequency, $\mathrm{IF}=$ intromission frequency, $\mathrm{ML}=$ mount latency, $\mathrm{IL}=$ intromission latency, $\mathrm{EL}=$ ejaculation latency, $\mathrm{PEI}=$ post-ejaculatory interval, $\mathrm{EF}=$ ejaculation frequency, $\mathrm{PE}=$ penile erection

Table 2: Inhibition of $\alpha$-amylase by the test samples

\begin{tabular}{|c|c|c|c|c|c|c|c|c|}
\hline \multirow[t]{2}{*}{ Conc. } & \multirow{2}{*}{$\begin{array}{l}\text { ETOH } \\
\%\end{array}$} & \multicolumn{3}{|c|}{ EA } & \multicolumn{2}{|l|}{ C1 } & \multicolumn{2}{|c|}{ Acarbose } \\
\hline & & $I C_{50}$ & $\%$ & $I C_{50}$ & $\%$ & $I C_{50}$ & & $I C_{50}$ \\
\hline 20 & 13 & $>100$ & 25 & $65 \pm 0.50^{b}$ & 35 & $50 \pm 0.45^{a}$ & 45 & $30 \pm 0.18^{a}$ \\
\hline 40 & 16 & & 33 & & 45 & & 58 & \\
\hline 60 & 21 & & 47 & & 57 & & 72 & \\
\hline 80 & 23 & & 58 & & 65 & & 81 & \\
\hline 100 & 37 & & 67 & & 73 & & 89 & \\
\hline
\end{tabular}

Conc. in $\mathrm{mg} / \mathrm{mL}$ for $E T O H$ and $E A ; \mu g / m L$ for $C 1$ and Acarbose; Data are given as mean $\pm S E M(n=3)$; data with different letters are significantly different at $p<0.05$ 


\section{Antimicrobial activity of C1}

Figure 2 shows the results of the antimicrobial studies carried out on the isolated compound (C1) and the standard drugs, with methanol as negative control.

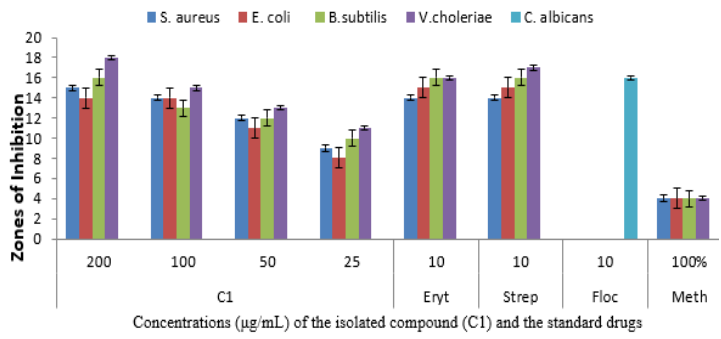

Figure 2: Antimicrobial profile of the isolated compound (C1), standard and control drugs. Key: C1 $=$ Isolated compound, Eryt = Erythromycin, Floc = Fluconazole, Meth $=$ Methanol, $\mathrm{B}$. subtilis $=$ Bacillus subtilis, S. aureus = Staphylococcus aureus, E. coli = Escherichia coli, V. chloeriae = Vibrio choleriae, $\mathrm{C}$. albicans = Candida albicans

\section{DISCUSSION}

Phytochemical screening of the ethanol stem bark extract of Acacia auriculiformis indicated the presence of typical plant chemical constituents namely: saponins, terpenoids, alkaloids and flavonoids. C1 was isolated from the EA fraction of the ethanol extract as a light brown amorphous powder, with $\mathrm{mp}, 147^{\circ} \mathrm{C}$. The compound was elucidated by a combination of physical properties (melting point) and spectroscopic analyses. FTIR absorption at 3295 $\mathrm{cm}^{-1}$ indicated the presence of $\mathrm{OH}$ from carboxylic acid; $11699.7 \mathrm{~cm}^{-1}$ indicated $\mathrm{C}=\mathrm{O}$ from carboxylic acid and the absorption at 1606.0, indicated aromatic structure; while $838.7 \mathrm{~cm}^{-1}$ showed a para-substituted aromatic system [24], [25]. Thus, FTIR analysis suggested a structure of a para-substituted aromatic acid. The proton NMR showed the presence of two aromatic protons each at: $\delta_{H} 7.049 \mathrm{ppm}$ (deshielded), adjacent to $\mathrm{COOH}$ group and at $6.806 \mathrm{ppm}$ (upfield), adjacent to $\mathrm{CO}$ group on the benzene ring. The proton signals at $4.072 \mathrm{ppm} 1.794 \mathrm{ppm}$ and $0.900 \mathrm{ppm}$ are attributed to the propoxy side chain (see figure 1a). For the ${ }^{13} \mathrm{C}$ NMR: $\delta c$ $172.976 \mathrm{ppm}$ indicated signal for acids while the peaks at $162.765 \mathrm{ppm}, 134.224 \mathrm{ppm}$ and $129.033 \mathrm{ppm}$ are attributable to carbon atoms on the benzene. The peaks at $115.648 \mathrm{ppm}$ and 62.936 ppm 26.000 ppm and 16.036 ppm came from Con the side chain [24,25]. The FTIR, ${ }^{1} \mathrm{H}$ and ${ }^{13} \mathrm{C}$ NMR showed that the compound has 10 carbon atoms, a benzene ring with para substitution, one of which is a carboxylic acid group. These data and the melting collaborate aptly with the literature values for 4propoxybenzoic acid [26] hence C1 is identified as 4-propoxybenzoic acid or paraproproxybenzoic acid. From the result obtained, the extract, fractions and the isolated compound showed aphrodisiac activity that was not significantly different from that of the normal saline (the negative control drug) but lower than that of the standard drug (testosterone - positive control) indicating a weak aphrodisiac activity of the plant extract and the isolated compound. This result is not surprising because $A$. auriculiformis and its isolate - acasiaside- $B$, have been associated with spermicidal activity [14]. The isolated C1 dose-dependently inhibited the actions of $\alpha$-amylase implicated in the metabolism of carbohydrate in human body. Alpha amylase catalyses the breaking down of starch to disaccharides and oligosaccharides [20]. This inhibition of digestion of the carbohydrate in turn decreases the rise in postprandial hyperglycemia. It was observed that the antimicrobial inhibition of the test sample was concentration-dependent. The inhibition exhibited by the isolated compound compared favourably with that of the standard drugs with highest inhibition of $18.00 \pm 0.23 \mathrm{~mm}$ at $200 \mu \mathrm{g} / \mathrm{mL}$ against Vibrio choleriae (NCTC 5438)

\section{CONCLUSION}

The findings of this research reveal that the ethanol stem bark extract of Acacia auriculiformis contains a compound identified as 4propoxybenzoic acid that can inhibit bacterial growth and $\alpha$-amylase action indicating potentials for antibacterial and anti-diabetic activity respectively. Interestingly, all the samples tested showed no antifungal activity and very low aphrodisiac potentials.

\section{DECLARATIONS}

\section{Acknowledgement}

The authors are grateful to the heads of Departments of Pharmaceutical and Medicinal Chemistry and Pharmacology and Toxicology, Faculty of Pharmacy, University of Uyo, for providing space in laboratories for this work.

\section{Conflict of interest}

No conflict of interest is associated with this work.

\section{Contribution of authors}

We declare that this work was done by the 
authors named in this article and all liabilities pertaining to claims relating to the content of this article will be borne by the authors. Ekarika $\mathrm{C}$. Johnson conceived, designed the study, analyzed, interpreted the spectra, and wrote the manuscript; Richard A. Ukpe and Emmanuel I. Etim performed the physicochemical analyses; Olorunfemi A. Eseyin designed and supervised the anti-diabetic experiment; Tina Mboho carried out the extraction and antimicrobial study; Paschal C. Anthony performed the anti-diabetic experiment, Uwemedimoh F. Umoh collected and prepared the plant materials; Anwanabasi E. Udoh performed the aphrodisiac test. All authors read and approved the manuscript for publication.

\section{Open Access}

This is an Open Access article that uses a funding model which does not charge readers or their institutions for access and distributed under the terms of the Creative Commons Attribution License (http://creativecommons.org/licenses/by/ 4.0) and the Budapest Open Access Initiative (http://www.budapestopenaccessinitiative.org/rea d), which permit unrestricted use, distribution, and reproduction in any medium, provided the original work is properly credited.

\section{REFERENCES}

1. Narayan P. Phytoantibiotics- Antibiotics from plants https://www.biotecharticles.com 2018-07- 19. Retrieved June 18, 2020

2. Duffy CF, Power RF. Antioxidant and Antimicrobial properties of some Chinese plant extracts. International Journal of Antimicrobial agents. 2001. 527-529.

3. Baris O, Gulluce M, Sahin F, Ozer $H$, Kilic $H$, Ozkan $H$, Sokmen M, Ozbek, T. Biological activity of the essential oil and methanol extract of Achille abieberteini AfanAfan (Asteraceae). Turkish Journal of Biology. 2006; 30: 6573.

4. Hammer KA, Carson CF, Dunstan JA, Hale J, Lehmann $H$, Robinson CJ, Prescott SL, Riley TV Antimicrobial and anti-inflammatory activity of five Taxandria fragrans oil in vitro. Microbiology and Immunology 2008;52: 522-530.

5. Fabricant DS, Farnsworth NR. The value of plant use in traditional medicine of drug discovery 2001; 1: 69-75.

6. LittletonJ, Roger T, Falcone D. Novel approaches to plant drug discovery based on high thought pharmacological screening and genetic manipulation. Life Sciences 2005; 78: 467-475.

7. Iwu MW, Duncan AR, Okunji CO. New antimicrobials of plant origin- Perspective on new crops and new uses. ASHS press, Alexandria, 1999; 457-462.

8. Ncube NS, Afolayan AJ, Okoh Al. Assessment techniques of antimicrobial properties of natural compounds of plant origin; current methods and future trends. African Journal of Biotechnology 2008; 7(12): 1797-1806.

9. Burton $G W$, Joyce $D$, Ingold $K U$. Is vitamin $E$ the only lipid soluble chain leaving antioxidant in human blood plasma and erythrocyte membrane. Arch. Biochem Biophys. 1983; 222: 228-290.

10. Ghosh M, Sinhababu SP, Sukul NC. Antifilarial effect of two triterpenoid saponins isolated from Acacia auriculiformis; Indian Journal of experimental biology 1993; 31: 604-606.

11. Mandal $P$, Sinhababu SP, Mandal NC. Antimicrobial activity of saponins from Acacia auriculiformis. Fitoterapia 2005; 76: 462-465.

12. Girijashan KV. Micropropagation of multipurpose medicinal tree Acacia auriculiformis. Journal of medicinal plant research 2011; 5: 462-466.

13. Kabir SN, Ray HN, Pal BC, Mitra D. Pharmaceutical composition having virucidal and spermicidal activity. USPTO, patent application 2008; 20080300197.

14. Singh S, Sharmar N, Evaluation of wound healing activity of Acacia auriculiformis A. cunn stem bark. Asian Journal of Pharmaceutical and Clinical Research 2014; 7(2): 204-207.

15. Kaur A, Sohal SK, Singh R, Arora S. Development of inhibitory effect of Acacia auriculiformis extract on Bactroceracurcubitae. Journal of Biopesticide 2010; 3: 499-504.

16. Subramonian VM, Raasekharan S. Pushpangadan, $P$. Aphrodisiac Property of Trichopus zeylanicus 1997; 57: 211 - 217.

17. NIH (National Institutes of Health, U. S. A.). Guide for the Care and Use of Laboratory Animals. Washington DC: The National Academic Press. 2011, p 246.

18. Gauthaman K, Adaikan PA, Prasad RN. Aphrodisiac Properties of tribulus terrestris extract (Protodioscin) in normal and castrated rats. Life Sci 2002; 71: 1385-1396.

19. Johnson EC, Ilyas M, Eseyin OA, Etim El, Udobre AS, Udoh AE Edem EO. Isolation, characterization and antidiabetic potentials of oleanolic acid from the leaves of Aspilia africana (Pers) CD Adams (Asteraceae), J. Pharm. Med. Res 2016; 2(2): 62-65.

20. Gibson L, Khoury J, Lett. Appl. Microbiol. 1986; 3: 127129.

21. Murray $P$, Baron E, Pfaller M, Tenover F. Yolken R. Manual of Clinical Microbiology. 4th edition, American Society of Microbiology Press 1995; 967-970.

22. Chaki S, Ghosh B, Smarak B, Musfiqua M, Sukhen D, Sujata GD. Detection of various phytochemical compounds from seeds of Acacia auriculiformis for possibilities of obtaining potent antimicrobial agents. Int J Bioll Pharm Res 2015; 6(2): 120-128.

23. Lambert JL. Introduction to Organic Spectroscopy, Macmillan Publ. N.Y. (1987).

24. Spectroscopy Data Tables. Z:Ifileslclasseslspectroscopyltypical spectral charts.DOC. Retrieved June 16, 2020

Trop J Pharm Res, March 2021; 20(3): 619 
Johnson et al

25. Bio-rad Laboratories Inc. Spectra base compound id; = CTc YjnNa2cX spectraBase specrum ID = AnacOZuRfmi https://spectrabase.com/spectrum/ AnacOZuRfmi? Accessed June 16, 2020
26. Richardson BA, Voeller B, Anderson DJ. Use of nonoxynol-9 and changes in vaginal lactobacilli. $J$ Infect Dis 1998; 178: $441-448$ 